\title{
In-Plane Buckling Analysis of Asymmetric Curved Beam Using DQM
}

\author{
Ki-jun Kang ${ }^{1^{*}}$ and Cha-Sik Park ${ }^{1}$ \\ ${ }^{1}$ School of Mechanical Engineering, Hoseo University \\ 미분구적법(DQM)을 이용한 비대칭 곡선보의 내평면 좌굴해석 \\ 강기준 ${ }^{1^{*}}$, 박차식 $^{1}$ \\ ${ }^{1}$ 호서대학교 공과대학 기계공학부
}

\begin{abstract}
One of the efficient procedures for the solution of partial differential equations is the method of differential quadrature. This method has been applied to a large number of cases to circumvent the difficulties of programming complex algorithms for the computer, as well as excessive use of storage due to conditions of complex geometry and loading. Under in-plane uniform distributed load, the buckling of asymmetric curved beam with varying cross section is analyzed by using differential quadrature method (DQM). Critical load due to diverse cross section variation and opening angle is calculated. Analysis result of DQM is compared with the result of exact analytic solution. As DQM is used with small grid points, exact analysis result is shown. New result according to diverse cross section variation is also suggested.
\end{abstract}

요 약 편미분방정식해법을 위한 효일적인 방법 중의 하나는 미분구적법이다. 이방법은 복잡한 구조 및 하중에 따른 컴퓨터 용량의 과도한 사용뿐만 아니라, 복합알고리즘의 어려움 피하기 위해 많은 분야에 적용되어 왔다. 본 연구에 서는 내평면 등분포하중 하에서 단면적이 변하는 비대칭 곡선보의 좌굴 (buckling)을 미분구적법(DQM)으로 해석하였 다. 다양한 단면적 변화와 열림각 (opening angle)에 따른 임계하중을 계산하였다. DQM의 해석결과는 정확한 수학적 해법 (exact analytic solution)과 비교하였으며, $\mathrm{DQM}$ 은 적은 격자점 (grid point)을 사용하여 정확한 해석결과를 보여주 었다. 또한, 다양한 단면적 변화에 따른 새로운 결과를 제시하였다.

Key Words : Asymmetric Curved Beam, Critical Load, DQM, Exact Analytic Solution, In-Plane Buckling, Uniformly Distributed Load

\section{Introduction}

Owing to their importance in many fields of technology and engineering, the stability behavior of elastic curved beam has been the subject of a large number of investigations. Solutions of the relevant differential equations have traditionally been obtained by the standard finite difference or finite element methods. These techniques require a great deal of computer time as the number of discrete nodes becomes relatively large under conditions of complex geometry and loading. In a large number of cases, the moderately accurate solution which can be calculated rapidly is desired at only a few points in the physical domain. However, in order to get results with even only limited accuracy at or near a point of interest for a reasonably complicated problem, solutions often have dependence of the accuracy and stability of the mentioned methods on the nature and

This research was supported by the Academic research Fund of Hosses University in 2012 (2012-0233)

*Corresponding Author : Kijun Kang(Hoseo Univ.)

Tel: +82-10-5430-5813 email: kjkang@hoseo.edu

Received July 4, $2013 \quad$ Revised August 12, 2013

Accepted October 10, 2013 
refinement of the discretization of the domain.

Ojalvo et al. [1] studied the elastic stability of ring segments with a thrust or a pull directed along the chord. Vlasov [2] derived closed-form solutions such as for an arch, in which cross sections are allowed to warp non-uniformly along the beam axis, subject to in-plane bending and uniformly distributed radial loads. Papangelis and Trahair [3] conducted a theoretical study of the flexural-torsional buckling of doubly symmetric arches to confirm the predictions of Timoshenko and Gere [4] for arches in uniform compression and of Vlasov [2] for arches in uniform bending. Yang and Kuo [5] studied the static stability of curved beams using the principle of virtual displacements in a Lagrangian formulation with emphasis place on the effect of curvature, and they presented closed-form solutions for arches in uniform bending and uniform compression. In addition, different approaches were also presented by Kuo and Yang [6] to support their studies treating a curved beam as the composition of an infinite number of infinitesimal straight beams. Kang and Yoo [7] presented a theoretical study on the buckling of curved beams with the derivation of stability equations. Recently, Kang and Kim [8] studied the in-plane vibration analysis of asymmetric curved beams using DQM.

In the present work, the DQM which is a rather efficient alternate procedure for the solution of partial differential equations, introduced by Bellman and Casti [9], is used to analyze in-plane buckling of the asymmetric curved beam with varying cross section subjected to uniformly distributed radial loads. The critical loads are calculated for the member. Numerical results are compared with existing exact solutions where available.

\section{Governing Differential Equations}

The curved beam considered is shown in Fig. 1 under the uniform in ward radial pressure $q$. A point on the centroidal axis is defined by the angle $\theta$, measured from the left support, and the radius of the centroidal axis is

$R$. The tangential and radial displacements of the arch axis are $w$ and $u$, respectively.

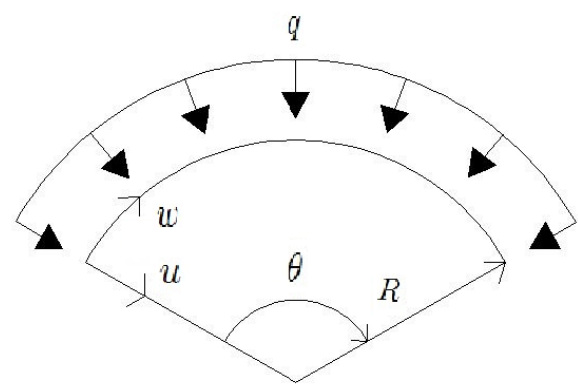

[Fig. 1] Coordinate system of curved beam with uniformly distributed radial load.

A mathematical study of the in-plane inextensional condition of small cross section is carried out starting with the basic equations as given by Love [10]. Following Love, the analysis is simplified by restricting attention to problems where there is no extension of the center line. This condition requires that $u$ and $w$ be related by

$$
w^{\prime}-\frac{1}{R} u=0
$$

If the external forces are assumed to rotate with the centroidal axis of the arch during the process of buckling, and shear deformation is neglected, the differential equation of curved beam subjected to uniformly distributed radial loads can be written as (Yang and Kuo [5])

$$
\begin{gathered}
\frac{E A}{R}\left(w^{\prime}+\frac{1}{R} u\right)+E I(\theta)\left(u^{I V}+\frac{2}{R^{2}} u^{\prime \prime}+\frac{1}{R^{4}} u\right) \\
-q R\left(u^{\prime \prime}-\frac{1}{R} w^{\prime}\right)=0
\end{gathered}
$$

where $E$ is the Young's modulus of elasticity for the material of the arch, and $I(\theta)$ is the area moment of inertia of the varying cross section.

Using equation (1) and the dimensionless distance coordinate $X=\theta / \theta_{0}$, in which $\theta_{0}$ is the opening angle of the member, one can rewrite equation (2) as

$$
\frac{w^{V}}{\theta_{0}^{5}}+2 \frac{w^{\prime \prime \prime}}{\theta_{0}^{3}}+\frac{w^{\prime}}{\theta_{0}}=\left(\frac{q R^{3}}{E I(X)}\right)\left(\frac{w^{\prime \prime \prime}}{\theta_{0}^{3}}+\frac{1}{\theta} w^{\prime}\right)
$$

where each prime denotes one differentiation with respect 
to the dimensionless distance coordinate.

Consider the beam structure with varying cross section shown in Fig. 2.

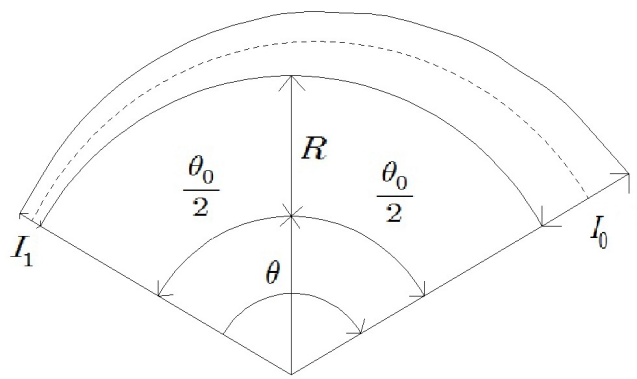

[Fig. 2] Curved beam with varying cross section.

Assuming, for instance, that the cross sectional moment of inertia for the left side of the beam varies along the length of the arc following three laws. Here, $I(\theta)$ varies linearly from $I_{1}$ at the left side to $I_{0}$ at the middle or the right side in terms of $\mathrm{X}$, respectively.

$$
\begin{aligned}
I(X)= & I_{0}(1-(1-\eta)(2(|X-0.5|))), \\
I(X)= & I_{0}(1+(1-\eta)(2(X-0.5))), \\
I(X)= & I_{0}(1+(1-\eta)(X-1.0)), \\
& 0 \leq X \leq 1
\end{aligned}
$$

where $\eta$ is the ratio of $I_{1} / I_{0}$.

The boundary conditions for both ends simply supported are,

$$
w=w^{\prime}=w^{\prime \prime \prime}=0 \text { at } X=0 \text { and } 1
$$

\section{Differential Quadrature Method}

The differential quadrature method (DQM) was introduced by Bellman and Casti [9]. By formulating the quadrature rule for a derivative as an analogous extension of quadrature for integrals in their introductory paper, they proposed the differential quadrature method as a new technique for the numerical solution of initial value problems of ordinary and partial differential equations. It was applied for the first time to static analysis of structural components by Jang et al. [11]. The versatility of the DQM to engineering analysis in general and to structural analysis in particular is becoming increasingly evident by the related publications of recent years. Kang and Han [12] applied the method to the analysis of a curved beam using classical and shear deformable beam theories, and Kang [13] studied the vibration analysis of curved beams using DQM, and Kang and Kim [14] studied the in-plane buckling analysis of curved beams using DQM. From a mathematical point of view, the application of the differential quadrature method to a partial differential equation can be expressed as follows:

$$
\begin{aligned}
L\{f(x)\}_{i}= & \sum_{j=1}^{N} W_{i j} f\left(x_{j}\right) \\
& \text { for } i, \quad j=1,2, \ldots, N
\end{aligned}
$$

where $L$ denotes a differential operator, $x_{j}$ are the discrete points considered in the domain, $i$ are the row vectors of the $N$ values, $f\left(x_{j}\right)$ are the function values at these points, $W_{i j}$ are the weighting coefficients attached to these function values, and $N$ denotes the number of discrete points in the domain. This equation, thus, can be expressed as the derivatives of a function at a discrete point in terms of the function values at all discrete points in the variable domain.

The general form of the function $f(x)$ is taken as

$$
f_{k}(X)=X^{k-1} \text { for } k=1,2,3, \ldots, N
$$

If the differential operator $L$ represents an $n^{\text {th }}$ derivative, then

$$
\begin{gathered}
\sum_{j=1}^{N} W_{i j} x_{j}^{k-1}=(k-1)(k-2) \cdots(k-n) x_{i}^{k-n-1} \\
\text { for } i, k=1,2, \ldots, N
\end{gathered}
$$

This expression represents $N$ sets of $N$ linear algebraic equations, giving a unique solution for the weighting coefficients, $W_{i j}$, since the coefficient matrix is a Vandermonde matrix which always has an inverse. 


\section{Application}

The DQM is applied to the determination of the in-plane buckling of the curved beam. The differential quadrature approximations of the governing equations and boundary conditions are shown.

Applying the differential quadrature method to equations (3), gives

$$
\begin{aligned}
& \frac{1}{\theta_{0}^{5}} \sum_{j=1}^{N} E_{i j} w_{j}+\frac{2}{\theta_{0}^{3}} \sum_{j=1}^{N} C_{i j} w_{j}+\frac{1}{\theta_{0}} \sum_{j=1}^{N} A_{i j} w_{j} \\
& =\left(\frac{q R^{3}}{E I\left(x_{i}\right)}\right)\left(\frac{1}{\theta_{0}^{3}} \sum_{j=1}^{N} C_{i j} w_{j}+\frac{1}{\theta_{0}} \sum_{j=1}^{N} A_{i j} w_{j}\right)
\end{aligned}
$$

where $A_{i j}, C_{i j}$, and $E_{i j}$ are the weighting coefficients for the first-, third-, and fifth-order derivatives, respectively, along the dimensionless axis.

The boundary conditions for simply supported ends given by equations (7) can be expressed in differential quadrature form as follows:

$$
\begin{array}{ll}
w_{1}=0 & \text { at } X=0 \\
w_{N}=0 & \text { at } X=1 \\
\sum_{j=1}^{N} A_{2 j} w_{j}=0 & \text { at } X=0+\delta \\
\sum_{j=1}^{N} A_{(N-1) j} w_{j}=0 & \text { at } X=1-\delta \\
\sum_{j=1}^{N} C_{3 j} w_{j}=0 & \text { at } X=0+2 \delta \\
\sum_{j=1}^{N} C_{(N-2) j} w_{j}=0 & \text { at } X=1-2 \delta
\end{array}
$$

Here, $\delta$ denotes a very small distance measured along the dimensionless axis from the boundary ends. In their work on the application of DQM to the static analysis of beams and plates, Jang et al. [11] proposed the so-called $\delta$-technique wherein adjacent to the boundary points of the differential quadrature grid points chosen at a small distance. This $\delta$ approach is used to apply more than one boundary conditions at a given station.

This set of equations together with the appropriate boundary conditions can be solved for the asymmetric curved beam with varying cross-section subjected to uniformly distributed radial loads.

\section{Numerical results and comparisons}

In-plane buckling parameters, $q^{*}\left(=\left(\theta_{0} / 2\right)^{2}\left(q_{c r} R^{3} / E I_{0}\right)\right)$, for the asymmetric curved beam with varying cross section are calculated by the DQM and are presented together with existing exact solutions. The values $q^{*}$ are evaluated for the case of various area moment of inertia of the varying cross sections and opening angles.

Table 1 presents the results of convergence studies relative to the number of grid points $N$ for the case of both ends simply supported with $\theta_{0}=60^{\circ}, 120^{\circ}$, and $180^{\circ}$ using Eq. 4 with $\eta=1.0$. The data show that the accuracy of the numerical solution increases with increasing $N$. Table 2 also shows the sensitivity of the solution to the choice of $\delta$ for the case of both ends simply supported using Eq. 4 with $\eta=1.0$. The optimal value for $\delta$ is found to be $1 \times 10^{-10}$, which is obtained from trial-and-error calculations. The solution accuracy decreases due to numerical instabilities if $\delta$ becomes too big (possibly greater than approx. $\left.1 \times 10^{-4}\right)$. The remainder of the numerical results are computed with both ends simply supported, 13 discrete points along the dimensionless X-axis, and $\delta=1 \times 10^{-10}$.

In Table 3 , the critical loads $q^{*}$ by the DQM [15] are compared with the solutions by Timoshenko and Gere [4]. Fig. 3 shows the critical loads $q^{*}$ by the DQM using Eq. 4 for the case of various varying cross sections and opening angles with both ends simply supported. Figs. 4 and 5 also show the critical loads $q^{*}$ by the DQM using Eqs. 5 and 6 , respectively without comparison since no data are available.

In Fig. 6, Critical loads $q^{*}$ by the DQM using Eqs. 4, 5 , and 6 , for the case of both ends simply supported with $\eta=0.5$, are compared with each other. In Table 4, First four critical loads $q^{*}$ by the DQM using Eqs. 5 and 6 are 
also presented. From Figs 3 - 5, it is seen that the critical buckling parameters $q^{*}$ can be increased by decreasing the opening angle $\theta_{0}$. The values $q^{*}$ are also increased by increasing the ratios $\eta=I_{1} / I_{0}$. Fig. 6 shows that the values $q^{*}$ are the highest when Eq. 4 is used, and the lowest when Eq. 6 is used. From Table 4, the high order critical loads $q_{1}^{*}-q_{4}^{*}$ can be also solved by the DQM. As can be seen, the numerical results by the DQM show good to excellent agreement with the exact solutions.

[Table 1] Critical load $q^{*}\left(=\left(\theta_{0} / 2\right)^{2}\left(q_{c r} R^{3} / E I_{0}\right)\right)$ of in-plane buckling of curved beam using Eq. 4 with both ends simply supported for a range of grid points $N ; \delta=1 \times 10^{-10}$ and $\eta=1.0$

\begin{tabular}{|c|c|c|c|c|c|}
\hline \multirow{2}{*}{$\theta_{0}$} & \multirow{2}{*}{$\begin{array}{c}\text { Timoshenko } \\
\text { and Gere [4] }\end{array}$} & \multicolumn{4}{|c|}{$\begin{array}{c}\text { Number of grid points } \\
\text { (DQM) }\end{array}$} \\
\cline { 3 - 6 } & & 7 & 10 & 13 & 16 \\
\hline 60 & 9.60 & 9.726 & 9.586 & 9.596 & 9.595 \\
\hline 120 & 8.77 & 8.903 & 8.763 & 8.773 & 8.773 \\
\hline 180 & 7.40 & 7.533 & 7.392 & 7.402 & 7.402 \\
\hline
\end{tabular}

[Table 2] Critical load $q^{*}\left(=\left(\theta_{0} / 2\right)^{2}\left(q_{c r} R^{3} / E I_{0}\right)\right)$ of in-plane buckling of curved beam using Eq. 4 with both ends simply supported for a range of $\delta ; N=13$ and $\eta=1.0$

\begin{tabular}{|c|c|c|c|c|c|}
\hline \multirow{2}{*}{$\theta_{0}$} & \multirow{2}{*}{$\begin{array}{c}\text { Timoshenko and } \\
\text { Gere }[4]\end{array}$} & \multicolumn{4}{|c|}{$\delta(\mathrm{DQM})$} \\
\cline { 3 - 6 } & & $10^{-4}$ & $10^{-7}$ & $10^{-10}$ & $10^{-13}$ \\
\hline 60 & 9.60 & 9.845 & 9.597 & 9.597 & 9.569 \\
\hline 120 & 8.77 & 8.950 & 8.778 & 8.773 & 8.761 \\
\hline 180 & 7.40 & 7.879 & 7.402 & 7.402 & 7.317 \\
\hline
\end{tabular}

[Table 3] Critical load $q^{*}\left(=\left(\theta_{0} / 2\right)^{2}\left(q_{c r} R^{3} / E I_{0}\right)\right)$ of in-plane buckling of curved beam using Eq. 4 with both ends simply supported; $\mathrm{N}=13$ and $\delta=1 \times 10^{-10}$

\begin{tabular}{|c|c|c|c|c|c|}
\hline$\theta_{0}$ & Comparisons & \multicolumn{4}{|c|}{$\eta=I_{1} / I_{0}$} \\
\cline { 3 - 6 } & & 0.2 & 0.4 & 0.6 & 0.8 \\
\hline \multirow{2}{*}{60} & $\begin{array}{c}\text { Timoshenko and } \\
\text { Gere [4] }\end{array}$ & 5.20 & 6.48 & 7.58 & 8.62 \\
\cline { 2 - 6 } & DQM & 5.263 & 6.494 & 7.591 & 8.617 \\
\hline \multirow{2}{*}{120} & $\begin{array}{c}\text { Timoshenko and } \\
\text { Gere [4] }\end{array}$ & 4.82 & 5.94 & 6.94 & 7.89 \\
\cline { 2 - 6 } 180 & DQM & 4.822 & 5.941 & 6.942 & 7.878 \\
\hline \multirow{2}{*}{18 Timoshenko and } \\
Gere [4] & 4.08 & 5.02 & 5.86 & 6.66 \\
\cline { 2 - 6 } & DQM & 4.083 & 5.019 & 5.860 & 6.648 \\
\hline
\end{tabular}

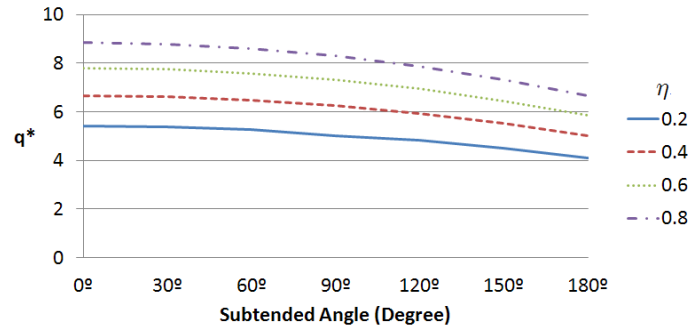

[Fig. 3] Critical load $q^{*}\left(=\left(\theta_{0} / 2\right)^{2}\left(q_{c r} R^{3} / E I_{0}\right)\right)$ of in-plane buckling of curved beam by DQM using Eq. 4 with both ends simply supported; $\mathrm{N}=13$ and $\delta=1 \times 10^{-10}$

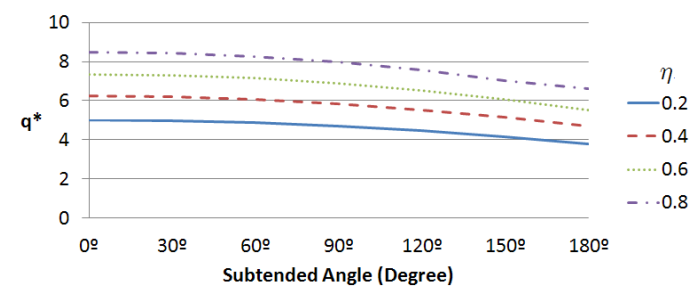

[Fig. 4] Critical load $q^{*}\left(=\left(\theta_{0} / 2\right)^{2}\left(q_{c r} R^{3} / E I_{0}\right)\right)$ of in-plane buckling of curved beam by DQM using Eq. 5 with both ends simply supported ; $\mathrm{N}=13$ and $\delta=1 \times 10^{-10}$

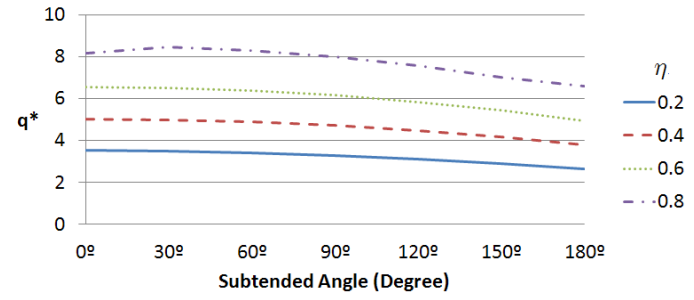

[Fig. 5] Critical load $q^{*}\left(=\left(\theta_{0} / 2\right)^{2}\left(q_{c r} R^{3} / E I_{0}\right)\right)$ of in-plane buckling of curved beam by DQM using Eq. 6 with both ends simply supported; $\mathrm{N}=13$ and $\delta=1 \times 10^{-10}$

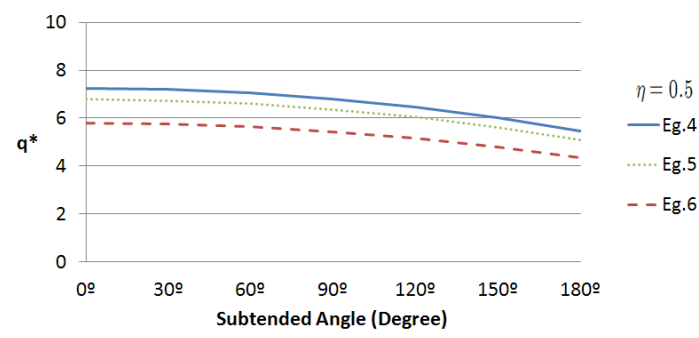

[Fig. 6] Critical load $q^{*}\left(=\left(\theta_{0} / 2\right)^{2}\left(q_{c r} R^{3} / E I_{0}\right)\right)$ of in-plane buckling of curved beam by DQM using Eqs. 4, 5 , and 6 with both ends simply supported ; $\mathrm{N}=13$, $\delta=1 \times 10^{-10}$, and $\eta=0.5$ 
[Table 4] First four critical load $q^{*}\left(=\left(\theta_{0} / 2\right)^{2}\left(q_{c r} R^{3} / E I_{0}\right)\right)$ of in-plane buckling of curved beam by DQM using Eqs. 5 and 6 with both ends simply supported ; $\mathrm{N}=13, \delta=1 \times 10^{-10}$, and $\eta=0.5$

\begin{tabular}{|c|c|c|c|}
\hline \multirow[t]{2}{*}{$\theta_{0}$} & \multirow{2}{*}{$q^{*}$} & \multicolumn{2}{|c|}{$\begin{array}{c}\eta=0.5 \\
(\mathrm{DQM})\end{array}$} \\
\hline & & Eq. 5 & Eq. 6 \\
\hline \multirow{4}{*}{60} & $q_{1}^{*}$ & 6.601 & 5.631 \\
\hline & $q_{2}^{*}$ & 18.72 & 14.73 \\
\hline & $q_{3}^{*}$ & 34.30 & 27.23 \\
\hline & $q_{4}^{*}$ & 55.21 & 42.67 \\
\hline \multirow{4}{*}{120} & $q_{1}^{*}$ & 6.039 & 5.154 \\
\hline & $q_{2}^{*}$ & 18.36 & 14.48 \\
\hline & $q_{3}^{*}$ & 33.83 & 26.79 \\
\hline & $q_{4}^{*}$ & 54.86 & 42.42 \\
\hline \multirow{4}{*}{180} & $q_{1}^{*}$ & 5.104 & 4.359 \\
\hline & $q_{2}^{*}$ & 17.86 & 14.17 \\
\hline & $q_{3}^{*}$ & 33.14 & 26.15 \\
\hline & $q_{4}^{*}$ & 54.43 & 42.11 \\
\hline
\end{tabular}

\section{Conclusions}

The differential quadrature method (DQM) was applied to the computation of the eigenvalues of the equations governing the asymmetric curved beam with varying cross section subjected to uniformly distributed radial loads. The present approach gives the followings.

1) The results by DQM give the good accuracy compared with existing analytic solutions by others for cases in which they are available.

2) Only thirteen discrete points are used for the evaluation. It has also been shown that compare to the finite element method using 90 elements, the DQM using 13 points was more accurate for the cases of vibration analysis of the beams [8\} (since other numerical methods are not available for the cases of the bucking).

3) It requires less than 1.0 second to compile the program with IMSL subroutine using the personal computer. The more detailed computation times for the evaluation of the structural characteristics were reported in totality by Kukreti et al. [16].

4) New result according to diverse cross section variation is also suggested.

\section{References}

[1] M. Ojalvo, E. Demuts and F. Tokarz, "Out-of-Plane Buckling of Curved Members", J. Struct. Dvi., ASCE, Vol. 95, pp. 2305-2316, 1969.

[2] V. Z. Vlasov, Thin Walled Elastic Beams, 2nd edn, English Translation, National Science Foundation, Washington, D.C., 1961.

[3] J. P. Papangelis and N. S. Trahair, "Flexural-Torsional Buckling of Arches", J. Struct. Engng, ASCE, Vol. 113, pp. 889-906, 1987.

DOI: http://dx.doi.org/10.1061/(ASCE)0733-9445(1987) 113:4(889)

[4] S. P. Timoshenko and J. M. Gere, Theory of Elastic Stability, 2nd edn, McGraw-Hill, New York, 1961.

[5] Y. B. Yang and S. R. Kuo, "Static Stability of Curved Thin-Walled Beams", J. Struct. Engng, ASCE, Vol. 112, pp. 821-841, 1986.

DOI: http://dx.doi.org/10.1061/(ASCE)0733-9399(1986) $\underline{112: 8(821)}$

[6] S. R. Kuo and Y. B. Yang, "New Theory on Buckling of Curved Beams", J. Engng Mech., ASCE, Vol. 117, pp. 1698-1717, 1991.

[7] Y. J. Kang and C. H. Yoo, "Thin-Walled Curved Beams, II: Analytical Solutions for Buckling of Arches", J. Struct. Engng, ASCE, Vol. 120, pp. 2102-2125, 1994.

DOI: http://dx.doi.org/10.1061/(ASCE)0733-9399(1994)

$$
\text { 120:10(2102) }
$$

[8] K. Kang and Y. Kim, "In-Plane Vibration Analysis of Asymmetric Curved Beams Using DQM", J. KAIS., Vol. 11, pp. 2734-2740, 2010.

[9] R. E. Bellman and J. Casti, "Differential Quadrature and Long-Term Integration", J. Math. Anal. Applic., Vol. 34, pp. 235-238, 1971.

DOI: http://dx.doi.org/10.1016/0022-247X(71)90110-7

[10] A. E. H. Love, A Treatise on the Mathematical Theory of Elasticity, 4th edn, Dover, New York, 1944.

[11] S. K. Jang, C. W. Bert and A. G. Striz, "Application of Differential Quadrature to Static Analysis of Structural Components", Int. J. Numer. Mech. Engng, Vol. 28, pp. 561-577, 1989. 
DOI: http://dx.doi.org/10.1002/nme.1620280306

[12] K. Kang and J. Han, "Analysis of a Curved beam Using Classical and Shear Deformable Beam Theories", Int. J. KSME., Vol. 12, pp. 244-256, 1998.

[13] K. Kang, "Vibration Analysis of Curved Beams Using Differential Quadrature", J. KIIS., Vol. 14, pp. 199-207, 1999.

[14] K. Kang and Y. Kim, "In-Plane Buckling Analysis of Curved Beams Using DQM", J. KAIS., Vol. 13, pp. 2858-2864, 2012.

DOI: http://dx.doi.org/10.5762/KAIS.2012.13.7.2858

[15] K. Kang and C. Park, "In-Plane Buckling Analysis of Curved Beams with Varying Cross-Section", RITE., Hoseo University, Vol. 31, pp. 21-29, 2012.

[16] A. R. Kukreti, et al., "Differential Quadrature and Rayleigh-Ritz Methods to Determine the Fundamental Frequency of Simply Supported Rectangular Plate with Linearly Varying Thickness ", J. Sound Vibr., Vol. 189, No. 1, pp. 103-122. 1996.

DOI: http://dx.doi.org/10.1006/jsvi.1996.0008

\section{Ki-Jun Kang}

[Regular Member]

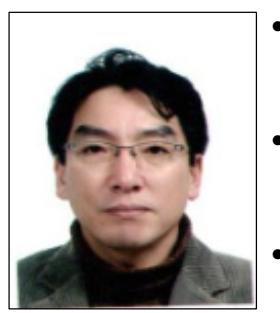

- Feb. 1984 : Chungnam National University, Dept. of Mechanical Engineering (B.S),

- Dec. 1989 : San Jose State University, Dept. of Mechanical Engineering (M.S)

- Dec. 1995 : University of Oklahoma, Dept. of Mechanical Engineering (Ph.D)

- Mar. $1997 \sim$ the present : Dept. of Automotive Engineering, Hoseo University, Professor

$<$ Research Interests $>$

Structural Analysis, Numerical Analysis, Buckling

\section{Cha-Sik Park}

[Regular Member]

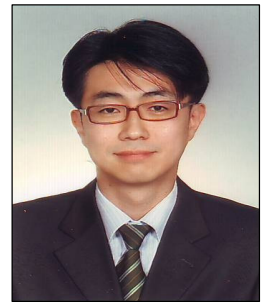

- Feb. 1991 : Kores University, Dept. of Mechanical Engineering (B.S),

- Feb. 1997 : Kores University, Dept. of Mechanical Engineering (M.S)

- Feb. 2007 : Kores University, Dept. of Mechanical Engineering (Ph.D)

- Mar. $2007 \sim$ the present : Dept. of Automotive Engineering, Hoseo University, Professor

$<$ Research Interests $>$

Fluids Dynamics, Numerical Analysis 